\title{
Pixerécourt, Mélodrames
}

\section{Lise Sabourin}

\section{OpenEdition}

\section{Journals}

\section{Edizione digitale}

URL: http://journals.openedition.org/studifrancesi/10654

DOI: 10.4000/studifrancesi. 10654

ISSN: 2421-5856

\section{Editore}

Rosenberg \& Sellier

\section{Edizione cartacea}

Data di pubblicazione: 1 décembre 2017

Paginazione: 557-558

ISSN: 0039-2944

\section{Notizia bibliografica digitale}

Lise Sabourin, «Pixerécourt, Mélodrames», Studi Francesi [Online], 183 (LXI | III) | 2017, online dal 01

février 2018, consultato il 26 janvier 2021. URL: http://journals.openedition.org/studifrancesi/10654; DOI: https://doi.org/10.4000/studifrancesi.10654

Questo documento è stato generato automaticamente il 26 janvier 2021.

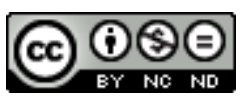

Studi Francesi è distribuita con Licenza Creative Commons Attribuzione - Non commerciale - Non opere derivate 4.0 Internazionale. 


\title{
Pixerécourt, Mélodrames
}

\author{
Lise Sabourin
}

\section{NOTIZIA}

RENÉ-CHARLES GUILBERT DE PIXERÉCOURT, Mélodrames, sous la direction de Roxane Martin, t. II. 1801-1803, édition de Stéphane Arthur, François Lévy, Roxane Martin, Gaël Navard, Sylviane Robardey-Eppstein et Maria Walecka-Garbalinska, Paris, Classiques Garnier, 2014, 1227 pp.

1 La grande entreprise lancée par Roxane Martin de publier les Mélodrames de Pixerécourt se poursuit avec ce tome II, introduit par un bref avant-propos et une chronologie de la période concernée, de 1801 à 1803, et clos par variantes, bibliographie, index des noms et des œuvres. Chaque pièce est précédée d'une présentation des circonstances d'écriture et de représentation, d'une analyse des motifs et de la pratique dramatique, d'une étude de réception à plus long terme et d'une note sur l'établissement du texte.

2 Le succès est toujours au rendez-vous pour le dramaturge, et de manière durable, mais sa tendance à accentuer le spectaculaire historique se marque nettement. Si tous ces mélodrames s'inspirent de romans que Pixerécourt adapte assez librement, il existe en effet un écart entre les trois premiers, d'intrigue essentiellement sentimentale, et les quatre suivants, fondés directement sur un épisode historique dramatisé de façon personnelle.

3 Le Pèlerin blanc, édité par Stéphane ARTHUR (pp. 23-148), entremêle les motifs romanesques des orphelins élevés dans une ferme à l'ombre d'un château gothique, des noces villageoises de paysans dévoués à leur bon seigneur parti guerroyer au loin, de son criminel intendant usurpateur, et de l'heureux retour du maitre assurant le salut général.

4 L'Homme à trois visages ou le Proscrit, que publie Sylviane ROBARDEY-EPPSTEIN (pp. 149-300), nous entraîne sur fond de fête vénitienne dans l'univers des Brigands de Schiller et de l'Abällino de Zschokk: les métamorphoses du proscrit permettent de réfléchir sur la 
frontière flottante entre bien et mal, sur le choix que doit accomplir le héros entre éthique et liberté, entre fins et usage des moyens, exemplaire grand homme chargé de «sauver la République» en pleine actualité consulaire.

5 Roxane MARTIN donne toute sa portée à La Femme à deux maris (pp.301-557) en y introduisant la partition musicale établie par Gaël NAVARD. La faiblesse de l'intrigue (cette veuve d'un brutal qui en l'enlevant l'avait fait maudire de son père, remariée à un doux comte qui se fait son défenseur lors de la réapparition du premier époux, pseudo-mort réclamant fils et château) fait comprendre combien la dimension spectaculaire de ce Mélo-Drame tenait au charme de la danse et au pittoresque des tableaux.

6 François LÉVY présente et annote Raymond de Toulouse ou le Retour de la Terre Sainte (pp. 561-649): quoique inspiré du Richard cœur de lion de Sedaine et Grétry et de Raoul, sire de Créqui de Monvel et Dabayrac, ce drame lyrique en trois actes eut un peu moins de succès.

7 En revanche, Pizarre ou la Conquête du Pérou, édité par Sylviane ROBARDEY-EPPSTEIN (pp. 651-769), combla les spectateurs par l'évocation de la cité des Incas, du conflit entre Espagnols et Péruviens sous l'œil critique de Las Casas, du débat entre Pizarre et Alonzo, adversaires qui s'estiment pour leur courage et s'unissent contre le maléfique Davila.

8 Maria WALECKA-GARBALINSKA donne tout son savoir national à l'annotation des Mines de Pologne (pp. 771-893), les variantes restant établies par Roxane Martin: ce sombre drame d'une épouse et mère enfermée par un haïssable rival de son héros de mari (librement adapté du Ladouski et Floriska de Lacroix) ajoutait à l'actualité polonomane tout le plaisir d'une intrigue où le couple de gardiens Ragotzi et Polina joue à échanger feinte serviabilité et brusque dévouement.

9 Stéphane ARTHUR enfin présente Tékéli ou le Siège de Montgatz (pp. 895-1012): si la censure s'abattit un temps sur ce «mélodrame historique en trois actes, en prose et à grand spectacle», selon la formule dramatique désormais adoptée par Pixerécourt, pleine de rythme et d'espace, de coups de théâtre à effet, le succès fut ensuite grand et durable tant les spectateurs appréciaient ce champion de l'indépendance hongroise qui osa en 1687 s'opposer aux Habsbourg, pourtant auréolés par leur résistance aux avancées ottomanes. 